\title{
Ascitic Fluid from Human Ovarian Cancer Patients Contains Growth Factors Necessary for Intraperitoneal Growth of Human Ovarian Adenocarcinoma Cells
}

\author{
Gordon B. Mills, * Christopher May, * Mary Hill,* Susan Campbell,* Patricia Shaw,‡ and Alexander Marks \\ *Oncology Research, Toronto General Hospital, Toronto, M5G2C4; ${ }^{\ddagger}$ Department of Pathology, University of Toronto and Sunnybrook \\ Medical Center, Toronto, M4N 3M5; ${ }^{\S}$ Banting and Best Department of Medical Research, University of Toronto, Toronto, Ontario,
}

Canada, M5G $1 L 6$

\begin{abstract}
Human ovarian cancer, the leading cause of death from gynecologic malignancy, tends to remain localized to the peritoneal cavity until late in the disease. In established disease, ascitic fluid accumulates in the peritoneal cavity. We have previously demonstrated that this ascitic fluid is a potent source of in vitro mitogenic activity including at least one unique growth factor. We now report that the human ovarian adenocarcinoma line, HEY, can be induced to grow intraperitoneally in immunodeficient nude mice in the presence $(23 / 28$ mice), but not absence (0/21 mice) of ascitic fluid from ovarian cancer patients. Ascitic fluid from patients with benign disease did not have similar effects on intraperitoneal growth of HEY cells (1/15 mice). Once tumors were established by injections of exogenous ascitic fluid, they could progress in the absence of additional injections of ascitic fluid. The mice eventually developed ascitic fluid which contained potent growth factor activity, suggesting that the tumors eventually produced autologous growth factors. This nude mouse model provides a system to study the action of ovarian cancer growth factors on tumor growth in vivo and to evaluate preclinically, therapeutic approaches designed to counteract the activity of these growth factors. ( $J$. Clin. Invest. 1990. 86:851-855.) Key words: ovarian cancer $\bullet$ ascites - growth factors
\end{abstract}

\section{Introduction}

Adenocarcinoma of the ovary is the leading cause of death from gynecologic malignancy $(1,2)$. Current therapy, which combines surgery, radiation, and chemotherapy, cures only a portion of patients. The high mortality is due predominantly to occult progression of the tumor with initial diagnosis usually made at an advanced stage when the disease is not responsive to therapy $(1,2)$. Tumor growth is characterized by local extension into the peritoneal cavity causing diffuse carcinomatosis and ascites $(1,2)$. In most cases, death results from cachexia or bowel obstruction as a result of the large intraperitoneal tumor burden. In order to improve the prognosis of ovarian cancer, novel therapeutic approaches are essential. To

Address correspondence and reprint requests to Dr. Gordon B. Mills, Department of Obstetrics and Gynecology, Oncology Research, CCRW 3-827, Toronto General Hospital, 200 Elizabeth Street, Toronto, Ontario M5G 2C4, Canada. 1990.

Received for publication 27 July 1989 and in revised form 18 April

\section{J. Clin. Invest.}

(c) The American Society for Clinical Investigation, Inc.

0021-9738/90/09/0851/05 $\$ 2.00$

Volume 86, September 1990, 851-855 develop these approaches for evaluation of therapeutic strategies, both an improved understanding of the pathophysiology of the disease and animal models are required.

We have previously demonstrated that ascitic fluid from ovarian cancer patients contains potent mitogenic activity in vitro for both primary cultures of human ovarian tumor cells and established human ovarian adenocarcinoma cell lines (3, 4). Although the activity has not been fully characterized, at least one of the growth factors contained in ascitic fluid appears to be unique (3). In order to develop an in vivo model to study the mitogenic activity of growth factors present in ascitic fluid, we examined the effect of ascitic fluid, from patients with ovarian cancer, on the growth of the human ovarian adenocarcinoma line, $\operatorname{HEY}^{1}(5)$, in the peritoneal cavity of immunodeficient nude mice. We demonstrated that cell-free ascitic fluid from ovarian cancer patients is obligatory for the intraperitoneal but not subcutaneous growth of HEY. This suggests that in the clinical situation, growth factors in ascitic fluid may promote the intraperitoneal extension of ovarian cancer in women afflicted with this malignancy. It also provides a model to characterize the mitogenic activities involved and to evaluate therapy designed to block the activity of these growth factors.

\section{Methods}

Media and stock solutions. Complete medium was RPMI 1640 (Gibco Laboratories, Grand Island, NY) supplemented with 5\% (vol/vol) FCS (Flow Laboratories Inc., Maclean, VA), 2 mM glutamine (Gibco Laboratories), and $5 \times 10^{-5} \mathrm{M}$ mercaptoethanol (Sigma Chemical Co., St. Louis, MO). $\left[{ }^{3} \mathrm{H}\right]$ Thymidine $(6.7 \mathrm{Ci} / \mathrm{mM})$ was from New England Nuclear (Lachine, Quebec). Unless stated otherwise, all other reagents were from Sigma Chemical Co.

Ascitic fluid. Ascitic fluid was obtained from 16 patients with mucinous or serous ovarian cystadenocarcinomas according to a protocol approved by the Research Ethics Committee of the Toronto General Hospital. Ascitic fluid was also obtained from patients with hepatic cirrhosis, as well as from a patient with idiopathic ascites. The ascitic fluid was rendered cell free by centrifugation and was acid treated at pH 3.0 for $2 \mathrm{~h}$. It was then dialyzed overnight against $25 \mathrm{mM} \mathrm{NaCl}, 20$ mM Hepes pH 7.4 under pressure in 3,000 mol wt cut-off tubing resulting in a twofold decrease in volume. The protein concentration of the dialysate from ovarian cancer patients ranged from 86 to 92 $\mathrm{mg} / \mathrm{ml}$ and from patients with benign disease, $17-32 \mathrm{mg} / \mathrm{ml}$. Four independent pools of ascitic fluid from four to six patients were tested in six independent experiments as well as samples from individuals.

Cells. HEY (5) was obtained from Dr. R. Buick (Ontario Cancer Institute, Toronto). The cells were grown as monolayers in complete medium and harvested by trypsinization using $0.1 \%$ trypsin in 150 $\mathrm{mM} \mathrm{NaCl}, 0.2 \mathrm{mM}$ EDTA, $10 \mathrm{mM}$ Na phosphate, $\mathrm{pH} 7.4$ (3-5).

1. Abbreviations used in this paper: HEY, a human ovarian adenocarcinoma line. 
$\left[{ }^{3} \mathrm{H}\right]$ Thymidine incorporation. HEY cells were incubated for $48 \mathrm{~h}$ in serum-free complete medium, harvested, and incubated at $1 \times 10^{4}$ cells/ml in $200 \mu \mathrm{l}$ of serum-free complete medium in 96-well flat bottom plates (Costar Data Packaging Corp., Cambridge, MA), as previously described $(3,4)$. The cells were cultured for $48 \mathrm{~h}$ in the presence of the indicated reagents and then for an additional $6 \mathrm{~h}$ with $1 \mu \mathrm{Ci} /$ well $\left[{ }^{3} \mathrm{H}\right]$ thymidine. $\left[{ }^{3} \mathrm{H}\right] \mathrm{Thymidine}$ incorporation was determined by harvesting onto glass fiber disks followed by scintillation counting.

Monoclonal antibody binding. Cells were seeded in 96-well tissue culture plates at a density of $5 \times 10^{3}$ cells/well and cultured for 4-5 d when they formed confluent monolayers. The cells were incubated successively with serial dilutions of HEY-specific monoclonal antibodies $(6,7)$, rabbit anti-mouse Ig antibody at a $1 / 500$ dilution, and finally ${ }^{125} \mathrm{I}$-labeled protein A, as previously described $(6,7)$.

Nude mouse experiments. 4-6-wk-old male and female nude mice of Balb/c or Swiss background were purchased from Charles River (St. Constance, Quebec) and used within 2 wk of arrival. All experiments using mice were performed according to procedures approved by the Toronto General Hospital Animal Care Committee. Mice were injected intraperitoneally with the indicated numbers of HEY cells. Beginning at the time of injection of HEY cells, the mice received daily injections of concentrated human ascitic fluid prepared as described above, or in the case of control mice, an equal volume of dialysis buffer. The mice were monitored for abdominal distension (ascites formation). Mice that developed distension were tapped, and the cells recovered from their peritoneal cavity were cultured and assayed for reactivity with monoclonal antibodies specific for HEY cells using immunohistochemistry $(8)$ or RIA $(6,7)$ modified as described above. Mice with either abdominal distension or subcutaneous tumor growth were killed and examined for the presence of intraperitoneal tumor nodules.

\section{Results}

Ascitic fluid from ovarian cancer patients induces the intraperitoneal growth of human tumor cells in nude mice. HEY did not form intraperitoneal tumors or produce ascites after intraperitoneal injection into nude mice $(0 / 21$ mice, Table I). However, $\sim$ one-half (12/21 mice) of mice injected with HEY cells eventually developed subcutaneous tumors at the site of the injection track and succumbed to their tumor. In contrast, most of the mice (23/28) that received daily injections of ascitic fluid from ovarian cancer patients developed abdominal distension, which was indicative of intraperitoneal tumor growth (Table I). Similar results were obtained in six independent experiments. On autopsy, all mice had detectable ascitic fluid and most had disseminated intraperitoneal tumors. Ascitic fluid from ovarian cancer patients promoted intraperitoneal HEY tumor growth with equal frequency in male and female mice of Balb/c and Swiss nude background, indicating that intraperitoneal tumor growth was not dependent on mouse strain or sex-related hormonal differences. Four stable cells lines (HEY $\mathrm{N}, \mathrm{AS1}$, A4, and A8) were established from cells harvested from the peritoneal cavity of mice with abdominal distension. These cell lines grew as monolayers in vitro with a pattern similar to that of HEY cells and reacted with monoclonal antibodies specific for HEY cells in a cell binding RIA (Table II) or by immunocytochemistry (not presented). Control mice which were not injected with HEY cells, but received 54 daily injections of ascitic fluid from ovarian cancer patients, did not develop abdominal distension or intraperitoneal tumors $(0 / 4$, not presented).

In contrast to the effects of ascitic fluid from ovarian cancer patients, ascitic fluid from two separate individuals
Table I. Effect of Benign and Malignant Ascitic Fluid on Intraperitoneal Tumor Growth

\begin{tabular}{llcc}
\hline \multicolumn{2}{c}{ Ascitic fluid source } & $\begin{array}{c}\text { Number of mice } \\
\text { with intraperitoneal } \\
\text { tumor growth* }\end{array}$ & $\begin{array}{c}\text { Time of onset } \\
\text { of abdominal } \\
\text { distension }\end{array}$ \\
\hline None & (Buffer) & $0 / 21^{8}$ & $d^{\ddagger}$ \\
Benign & (Pooled) & $1 / 4^{\top}$ & - \\
Benign & (Pooled 4X) & $0 / 4^{\prime}$ & $45(45)$ \\
Benign & (Individual) & $0 / 4$ & - \\
Benign & (Individual) & $0 / 3^{* *}$ & - \\
& Total benign & $1 / 15$ & - \\
Ovarian cancer & (Pooled) & & $32(17-56)$ \\
Ovarian cancer & (Individual) & $20 / 25$ & $29(28-30)$ \\
& Total ovarian & $3 / 3$ & 31
\end{tabular}

Mice were injected intraperitoneal with $1 \times 10^{6}$ HEY cells followed by daily injections of $0.5 \mathrm{ml}$ of concentrated human ascitic fluid or buffer for 19-28 d. Results are from six independent experiments.

* Number of mice with intraperitoneal tumors/number of mice injected.

‡ Values indicate means and ranges.

12/21 mice developed tumors along the injection tract.

"Four times as much ascitic fluid $(2 \mathrm{ml} / \mathrm{d})$ was injected.

3/8 mice developed large subcutaneous tumor masses which extended into the peritoneal cavity. Although no ascitic fluid was detectable, HEY cells could be isolated from the peritoneal cavity likely as a result of shedding from the tumor mass.

** 1/3 mice developed tumors along the injection tract.

with hepatic cirrhosis or a pool of ascitic fluid from four patients with benign ascites did not support the intraperitoneal growth of HEY cells in nude mice (Table I). However, one mouse did develop multiple small subcutaneous tumors and a small amount of ascitic fluid (1/11). In one experiment, the mice were injected with four times the volume $(2 \mathrm{ml})$ of concentrated ascitic fluid from patients with benign disease than from patients with ovarian cancer to compensate for the higher protein concentration in the latter preparation. These mice did not develop ascites $(0 / 4$, Table I) either.

Mice injected with higher numbers of HEY cells tended to develop abdominal distension and intraperitoneal tumors more rapidly than those injected with lower numbers of HEY cells (Table III). This suggests that while ascitic fluid from ovarian cancer patients was required to initiate intraperitoneal

Table II. Binding of Anti-HEY Monoclonal Antibodies by Cell Lines Isolated from Nude Mice

\begin{tabular}{lcccc}
\hline & HEY & HEY AS1 & HEY A4 & HEY A8 \\
\hline 8C & 6 & 8 & 7 & 8 \\
10B & 3 & 4 & 4 & 4 \\
M2A & 3 & 4 & 3 & 4 \\
M2D & 3 & 4 & 3 & 8 \\
\hline
\end{tabular}

Confluent monolayers of the indicated cell lines were incubated with the indicated monoclonal antibodies, followed by rabbit anti-mouse Ig antibody and ${ }^{125} \mathrm{I}$-protein $\mathrm{A}$ as described in Methods. The values indicate ${ }^{125} \mathrm{I} \mathrm{cpm} \times 10^{-3}$ at a monoclonal antibody concentration of $0.1 \mu \mathrm{g} / \mathrm{ml}$ and represent $\sim 50 \%$ maximal binding for each antibody. 
Table III. Effect of Ascitic Fluid from Ovarian Cancer Patients on Intraperitoneal Tumor Growth

\begin{tabular}{ccccc}
\hline & & \multicolumn{2}{c}{$\begin{array}{c}\text { No. of mice with } \\
\text { intraperitoneal } \\
\text { tumor growth* }\end{array}$} & \\
\cline { 3 - 4 } $\begin{array}{c}\text { No. of } \\
\text { HEY cells } \\
\text { injected }\end{array}$ & $\begin{array}{c}\text { No. of injections } \\
\text { of ascitic fluid } \\
\text { or buffer }\end{array}$ & $\begin{array}{c}\text { Ascitic } \\
\text { fluid }\end{array}$ & Buffer & $\begin{array}{c}\text { Time of onset } \\
\text { of abdominal } \\
\text { distension }\end{array}$ \\
\hline & & & & $d^{\ddagger}$ \\
$1 \times 10^{6}$ & 22 & $9 / 10$ & $0 / 10$ & $31(17-53)$ \\
$5 \times 10^{5}$ & 24 & $6 / 6$ & $0 / 6$ & $33(16-58)$ \\
$2.5 \times 10^{5}$ & 44 & $5 / 5$ & $0 / 5$ & $58(44-66)$ \\
\hline
\end{tabular}

Mice were injected intraperitoneal with the indicated number of HEY cells followed by daily injections of $0.5 \mathrm{ml}$ of concentrated ascitic fluid from ovarian cancer patients or buffer. Results are from three independent experiments.

* Number of mice with intraperitoneal tumors/number of mice injected.

$\ddagger$ Values indicate means and ranges.

proliferation of HEY cells, once intraperitoneal tumor growth was established, it progressed in the absence of exogenous human ascitic fluid. However, mice receiving longer durations of daily injections of human ascitic fluid tended to develop abdominal distension and intraperitoneal tumors more rapidly than mice receiving a shorter duration of ascitic fluid injections (Table IV), indicating an effect of human ascitic fluid on tumor progression as well as on tumor initiation.

Mechanisms underlying intraperitoneal growth of $\mathrm{HEY}$ cells. As demonstrated above, although initiation of tumor growth was dependent on exogenous human ascitic fluid, progression of intraperitoneal HEY tumors in nude mice could occur in the absence of additional exogenous human ascitic fluid. Ascitic fluid isolated from the peritoneal cavity of HEY tumor-bearing nude mice, at least $2 \mathrm{wk}$ after the final injection of human ascitic fluid, contained mitogenic activity for HEY cells in vitro (Fig. 1). The mitogenic activity contained in the ascitic fluid from HEY tumor-bearing mice was considerably more potent than corresponding dilutions of ascitic fluid de-

Table IV. Effect of Duration of Injections of Ascitic Fluid from Ovarian Cancer Patients on Intraperitoneal Tumor Growth of HEY Cells

\begin{tabular}{ccc}
\hline $\begin{array}{c}\text { No. of daily injections } \\
\text { of ascitic fluid }\end{array}$ & $\begin{array}{c}\text { No. of mice with } \\
\text { intraperitoneal tumor } \\
\text { growth }\end{array}$ & $\begin{array}{c}\text { Time of onset } \\
\text { of abdominal } \\
\text { distension }\end{array}$ \\
\hline & & $d^{\ddagger}$ \\
7 & $4 / 4$ & $44(43-52)$ \\
14 & $3 / 4$ & $41(41-43)$ \\
21 & $3 / 3$ & $39(32-43)$ \\
28 & $3 / 3$ & $34(32-48)$
\end{tabular}

Mice were injected intraperitoneally with $1 \times 10^{6} \mathrm{HEY}$ cells followed by the indicated number of daily injections of concentrated ascitic fluid from ovarian cancer patients.

* Number of mice with intraperitoneal tumors/number of mice injected.

$\ddagger$ Values indicate means and ranges. rived from patients with ovarian cancer (Fig. 1). This is likely due to inhibitory growth activity contained in the ascitic fluid of some patients (4). Therefore, ascitic fluid from nude mice with progressively growing HEY tumors contains potent mitogenic activity that stimulates the proliferation of HEY cells in vitro and likely plays a role in the in vivo progression of the tumor growth.

Further evidence differentiating the mechanisms underlying the induction and progression of intraperitoneal HEY tumors was obtained using the stable cell lines (HEY N, AS1, $\mathrm{A} 4$, and A8) derived from cells harvested from the peritoneal cavity of mice with HEY cell tumors, which had been initiated by ascitic fluid from ovarian cancer patients. These cell lines were responsive to mitogenic stimulation by human ascitic fluid in vitro in a manner similar to the parental HEY cells (Figs. 1 and 2). However, in contrast to the parental HEY cells, the HEY N, AS1, A4, and A8 cell lines were capable of forming intraperitoneal tumors in mice in the absence of exogenous human ascitic fluid (Table V). Therefore, although the cell lines were responsive to exogenous growth factors in ascitic fluid from ovarian cancer patients in vitro, they no longer required human ascitic fluid to initiate intraperitoneal tumor growth on reinjection into nude mice.

\section{Discussion}

Ascitic fluid from human ovarian cancer patients, but not from patients with benign ascites, induced intraperitoneal growth of the human ovarian cancer cell line, HEY, in nude mice. This extends our previous observations that ascitic fluid from ovarian cancer patients, but not from patients with benign disease, had several specific effects on HEY cells in vitro including growth stimulation, activation of phospholipase $\mathrm{C}$, and induction of changes in cytosolic free calcium (3). These biochemical processes have been associated with the action of several different polypeptide hormones, growth factors, and oncogenes (9-11). These results suggest that ascitic fluid from ovarian cancer patients contains specific growth factors that can stimulate the growth of HEY cells both in vitro and in vivo in nude mice.

Although there was a requirement for exogenous ascitic fluid from ovarian cancer patients to initiate the intraperitoneal growth of HEY cells in nude mice, progression of established tumors was independent of exogenous ascitic fluid. This appeared to result from a selection of a cell population that did not require exogenous growth factors for intraperitoneal growth since the HEYN, AS1, A4, and A8 cell lines established from mice with progressive HEY tumors were able to grow intraperitoneal on reinjection into nude mice in the absence of exogenous human ascitic fluid. This selection may be based on the ability to produce autologous growth factors since ascitic fluid from mice with progressive tumors induced proliferation of HEY cells in vitro. Since exogenous growth factors are rapidly cleared from the peritoneal cavity with a half-life measured in minutes to hours $(12,13)$, it is unlikely that the growth-promoting activity present in ascitic fluid from nude mice was due to persistence of growth factors present in the injected ascitic fluid from ovarian cancer patients. However, although the HEYN, AS1, A4, and A8 cell lines were able to form intraperitoneal tumors in nude mice in the absence of 


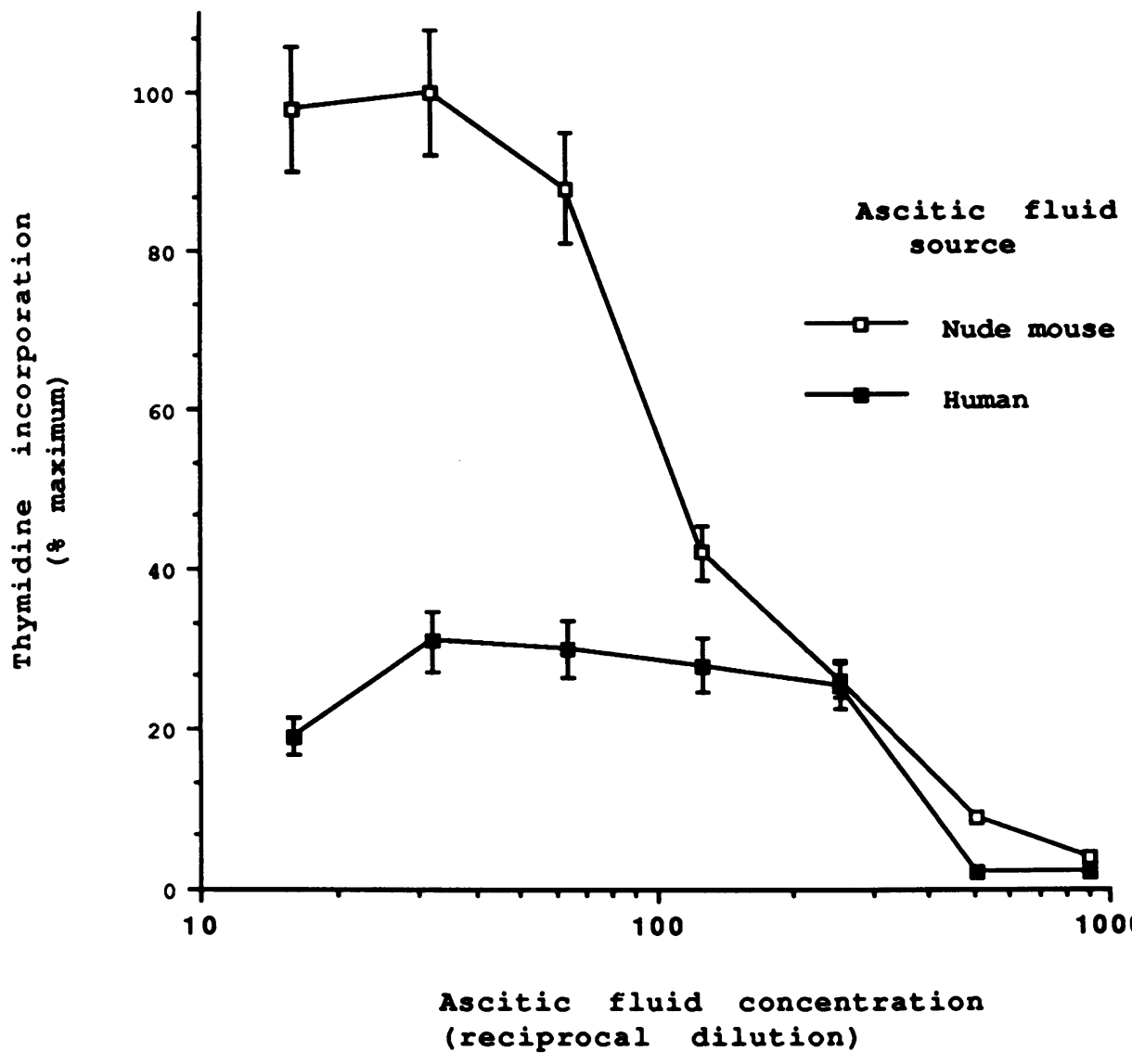

Figure 1. Comparison of mitogenic activity in ascitic fluid from nude mice to patients with ovarian carcinoma on HEY cells. HEY cells $\left(2 \times 10^{5} / \mathrm{ml}\right)$ were cultured in RPMI 1640 for $24 \mathrm{~h}$ with the indicated dilution of ascitic fluid from ovarian cancer patients or from nude mice. $\left[{ }^{3} \mathrm{H}\right]$ Thymidine $(1$ $\mu \mathrm{Ci} /$ well) was added and cells were harvested $6 \mathrm{~h}$ later. $\left[{ }^{3} \mathrm{H}\right] \mathrm{Thymidine}$ incorporation was determined by scintillation counting. The results represent the mean \pm SEM of three replicates. Maximum thymidine incorporation was $12,200 \pm 2300 \mathrm{cpm}$.

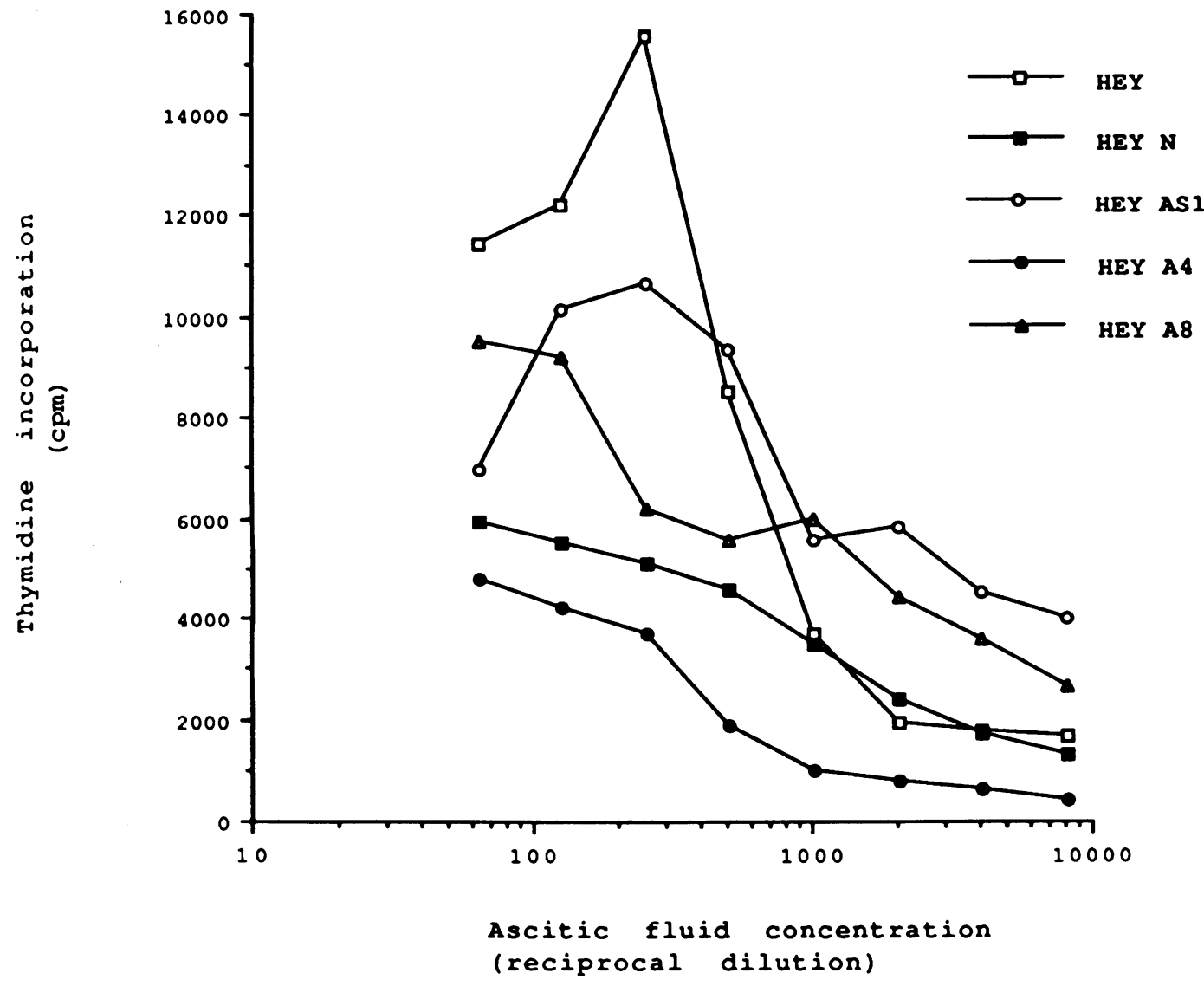

Figure 2. Mitogenic activity of ascitic fluid from ovarian cancer patients on proliferation of HEY sublines derived from tumor-bearing nude mice. HEY cells and the four HEY sublines isolated from nude mice with progressing tumors were cultured $\left(2 \times 10^{5}\right)$ $\mathrm{ml}$ ) in RPMI 1640 for 24 $h$ in the presence of the indicated concentrations of ascitic fluid from ovarian cancer patients. $\left[{ }^{3} \mathrm{H}\right]-$ Thymidine $(1 \mu \mathrm{Ci} /$ well $)$ was added and cells were harvested $6 \mathrm{~h}$ later. $\left[{ }^{3} \mathrm{H}\right]-$ Thymidine incorporation was determined by scintillation counting. The results represent the mean of three replicates. SEM was $<15 \%$. The results are representative of six similar experiments. 
Table V. Intraperitoneal Tumorgenicity

of HEY Sublines Derived from Tumor-bearing Mice

\begin{tabular}{lcc}
\hline Tumor line & $\begin{array}{c}\text { No. of mice with } \\
\text { intraperitoneal tumor growth* }\end{array}$ & $\begin{array}{c}\text { Time of onset } \\
\text { of abdominal } \\
\text { distension }\end{array}$ \\
\hline & & $d^{\ddagger}$ \\
HEY N & $4 / 5$ & $54(53-58)$ \\
HEY AS1 & $4 / 4$ & $39(38-43)$ \\
HEY A4 & $3 / 3$ & $43(41-44)$ \\
HEY A8 & $3 / 4$ & $32(30-34)$
\end{tabular}

Mice were injected intraperitoneally with $1 \times 10^{6}$ of the indicated cell lines.

* Number of mice with intraperitoneal tumors/number of mice injected.

$\ddagger$ Values indicate means and ranges.

exogenous human ascitic fluid, they demonstrated a similar in vitro response to growth factors in ascitic fluid from ovarian cancer patients as did the parental HEY line. Therefore, the HEYN, AS1, A4, and A8 cell lines retained receptors for growth factors present in ascitic fluid from ovarian cancer patients. This is also supported by the observation that tumor progression was more rapid in animals that received continuous injections with exogenous human ascitic fluid than in mice in which the injections were stopped after an initial course of 7 d. Serum-free supernatants from the parental HEY line and from the HEYN, AS1, A4, and A8 lines did not stimulate the growth of HEY cells in vitro.

In summary, our data indicate that growth factors present in ascitic fluid from ovarian cancer patients are required for the induction of intraperitoneal growth of human ovarian adenocarcinoma cells in nude mice. Therefore, it is possible that these growth factors also promote the growth of human ovarian cancer in the peritoneal cavity of women afflicted with this malignancy, which may explain the propensity of human ovarian cancer to remain confined to the peritoneal cavity until late in the disease. Our nude mouse model also provides a system to study the biology of intraperitoneal tumor growth and the in vivo interaction between human ovarian cancer cells and growth factors contained in ascitic fluid from human ovarian cancer patients. These growth factors represent a logical target for therapy of ovarian cancer. Blocking growth factors in ascitic fluid from ovarian cancer patients or conjugating appropriate purified growth factors to toxins or radioligands may provide effective therapeutic approaches against ovarian cancer that could be evaluated preclinically in this nude mouse model.

\section{Acknowledgments}

We thank J. Law, M. Lei, and the staff of the animal care unit of the Toronto General Hospital for technical assistance. Dr. Mills is a Medical Research Council of Canada Scholar and a McLaughlin Scientist.

This research was supported by the Medical Research Council of Canada, the National Cancer Institute of Canada, and the Genesis Foundation.

\section{References}

1. Richarsdon, G: S., R. E. Scully, N. Nikrui, and J. H. Nelson. 1985. Common epithelial cancer of the ovary (first of two parts). $N$. Engl. J. Med. 312:415-424.

2. Richarsdon, G. S., R. E. Scully, N. Nikrui, and J. H. Nelson. 1985. Common epithelial cancer of the ovary (second of two parts). $N$. Engl. J. Med. 312:474-483.

3. Mills, G. B., C. May, M. McGill, M. Roifman, and A. Mellors. 1988. Ascitic fluid from ovarian cancer patients contains a putative new growth factor: identification, characterization and mechanism of action. Cancer Res. 48:1066-1071.

4. Mills, G. B., and C. May 1989. Regulatory mechanisms in ascitic fluid. In Ovarian Cancer: Biologic and Therapeutic Challenges. F. Sharpe, W. P. Mason, and R. E. Leake, editors. Chapman and Hall Ltd., London. 55-62.

5. Buick, R. N., R. Pullano, and J. M. Trent. 1985. Comparative properties of five human ovarian carcinoma cell lines. Cancer Res. 45:3668-3676.

6. Baumal, R., J. Law, R. N. Buick, H. Kahn, H. Yeger, K. Sheldon, T. Colgan, and A. Marks. 1986. Monoclonal antibodies to an epithelial ovarian adenocarcinoma: distinctive reactivity with xenografts of the origional tumor and cultured cell line. Cancer Res. 46:3994-4000.

7. Sheldon, K., A. Marks, and R. Baumal. 1987. Characterization of binding of four monoclonal antibodies to the human ovarian adenocarcinoma cell line HEY. Biochem. Cell Biol. 65:423-428.

8. Shaw, P., R. Buckman, J. Law, R. Baumal, and A. Marks. 1988. Reactivity of tumor cells in malignant effusions with a panel of monoclonal and polyclonal antibodies. Tumor Biol. 9:101-109.

9. Varmus, H. E. 1984. The molecular gentics of cellular oncogenes. Annu. Rev. Genet. 18:553-561.

10. Sporn, M. B., and A. B. Roberts. 1985. Autocrine growth factors and cancer. Nature (Lond.). 313:745-747.

11. Mills, G. B. 1990 . Activation of lymphocytes by lymphokines. In Current Topics in Membranes and Transport. S. Grinstein and O. Rotstein, editors. Academic Press, San Diego, CA. 35:495-535.

12. Paetkau, V., G. B. Mills, and C. Bleackley. 1982. Enhancement of antitumor responses with interleukin 2. In The Potential Role of T Cell Populations in Cancer Therapy. M. A. Fefer and A. Goldstein, editors. Raven Press, Ltd., New York. 147-159.

13. Lotze, M. T., Y. L. Matory, Y. L. Ettinghausen, A. A. Rayner, S. O. Sharrow, C. A. Y. Seipp, M. C. Custer, and S. A. Rosenberg. 1985. In vivo administration of purified human interleukin 2. II. Half life, immunologic effects, and expansion of peripheral lymphoid cells in vivo with recombinant IL2. J. Immunol. 135:2865-2875. 